\title{
Expansion and Improvement of English Language in Scientific Domain with Respect to Globalization and Related Criticisms (A Case study)
}

\author{
Faezeh Bohlool \\ School of Anthropology, University of Tehran, PO Box: 773/14395, \\ Jalal Al-e Ahmad Highway, Tehran, Iran
}

\begin{abstract}
The present paper focuses on the topic of English language teaching and its widespread uses in the country's educational system, especially in the domain of science. Concerning the issue of globalization and the spread of communications in all areas, it seems that the need for an international language is felt more than ever. In this regard, the science domain has not been an exception and has entered the course of globalization concurrent with the world. The current case study conducted on 20 students of Anthropology studying at the University of Tehran, investigates two main problems. First, students' degree of satisfaction with the education presented by schools and universities, and their opinion about the English courses in Iran. In this article, we tried to capsulate their true ideas and suggestions for improving the teaching system of the English language in schools and universities according to their experiences. Second, we examined their feedback on the criticisms and disagreements against language expansion, such as linguistic imperialism and subtractive bilingualism.
\end{abstract}

Keywords: Expansion of English Language, Globalization, linguistic imperialism, Subtractive Bilingualism, Mother Tongue and Culture

DOI: $10.7176 / \mathrm{JLLL} / 82-03$

Publication date:October $31^{\text {st }} 2021$

\section{Introduction}

There are over 7100 languages in the world that we have not even heard of or dealt with. However, since we are living in a world of communications, we need an intermediate language to communicate with the people speaking these languages. This role has been played by English. Although English was the language belonging to a certain country, its expansion as an international language has questioned its ownership. Today, English is recognized as a language not belonging to a specific country and is used for global, political, cultural, and financial exchanges (Naji Meidani, Pishghadam, 2013). Hence, the roles societies, especially educational systems, play in familiarizing individuals with this language are highly significant.

There are numerous reasons for teaching English as an international language; for example, global communications, occupations, entertainment, and cultural exchanges. However, a paramount reason, which is the topic examined in this paper, is the need for this language in educational and scientific domains, wherein the international language has significant contributions. Accordingly, we can argue that the English language occupies a higher position than the mother tongue especially among the university students. It is because the scientific world is a global system in which ample information and communication transfers take place by the English language. Papers, books, journals, and even videos available in this domain are introduced by this language, and many of them are not often translated into students' first languages. On the other hand, if there exist even translations for these subjects, the principles of the scientific world expect individuals to comprehend these concepts in the main language and be able to provide feedback within that language. The inability to perceive such a language is a big barrier for students and scientists.

According to the importance of the English language in science one may ask to what extent teaching at different educational levels in Iran provides English for the students. At present, the educational system of Iran faces three fundamental problems in language teaching: 1) Language teachers are unspecialized in many cases. They are engaged with language teaching while being graduated from other fields. The teacher undertakes a significant role in teaching any field, and the methods and instruments he applies for teaching can accompany different impacts. Besides, the teacher's attitude crucially contributes to determining the success of a new method in language teaching. If the teacher perceives the change as threatening, he will not accept it easily. However, if he recognizes the changes as the facilitators of performance and reinforcers of his role, he will support them (Tomlinson, 2005, p. 142). Thus, the presence of specialized teachers who accentuate their responsibilities and exploit new methods to make their teaching more efficient is essential. 2) The textbooks of schools and universities lack standard designs. Unlike other countries wherein language learning is founded on interaction and communication, Iranian books are designed based on grammar and text reading mainly due to preparing students for attending the entrance exams of universities. Of course, this purpose of school teaching has not been successful, and many students turn to private institutions to learn the language. 3) The educational 
hours of language classes are inadequate at schools and universities. The language in the Iranian educational system is taught at a limited time with finite topic ranges. Students in Iranian schools do not learn the language as a means to learning other fields and only learn vocabulary, grammar, and reading ordinary texts at a short allocated time.

This paper endeavors to examine these problems from students' prospects and seeks to discover methods for enhancing efficiency and improving the educational system of the country.

\section{Theoretical Framework}

One of the problems concerned in the modern world is globalization, which impacts the daily and social lives of individuals differently and in varying dimensions, and its role becomes bolder day by day. In Anthony Giddens' belief, we live in a world of changes, a world that influences all dimensions of our lives. Good or bad, we are being pushed into a global order nobody knows it thoroughly. Globalization was a term rarely used until the late 1980s, neither in academic transcriptions nor daily lives. However, it boosted suddenly and is now considered in different fields of sciences and social problems (Giddens, 1999). Whatever it is, globalization is a concept that has shadowed the various areas of our daily and professional lives, and its sense becomes more vivid and tangible day by day. On its way, this process has reached economic, social, political, cultural, linguistic, and, finally, education domains. The current academic globe is an interconnected world manifesting the concept of globalization. Language plays a significant role in such a system. It is the source of communication in the human world, and the more difficult and complicated are the concepts, the bolder is the contribution of language. In such conditions, the scientific world employs a mutual language to create extensive and understandable communications among all individuals working in this domain. This language in the present world is English, whose full mastery constitutes the primary principles of entering the professional world of science. Therefore, the language teaching problem and its correct implementation are the issues that need attention.

Institutions and schools all over the world consider different methods for language teaching. Teaching standards are the subject of change at different periods, and a certain method is employed in every period, the methods that are often recognized as learning strategies. Research on the language learning strategies, which were initially descriptive in most cases, commenced in the 1980's and 1990's. Learning strategies are the methods that facilitate the language learning task. These strategies are often conscious and goal-oriented, especially in the initial phases of familiarity with an unknown language (Chamot, 2005). Language strategies are of varying types. For example, in a categorization, O'Malley and Chamot introduced three language strategies. The first is the metacognitive strategy which includes being aware of the learning process and controlling it. In this method, the individual plans to learn and supervise his learning process. Put differently, he is conscious of his learning process and thinks about it. The second strategy is cognitive, which encompasses those individuals who attempt to calculate and perceive the certain information they are given. These individuals acquire language and enhance their perceptions by assimilating and accommodating. In the last strategy, called the social-affective strategy, individuals use language realistically. In this method, social interactions are used for learning and memorizing linguistic information, and personal impressions are integrated with language learning problems (O'Malley \& Chamot, 1990). In addition to these three strategies, there are other cases that can be applied as language teaching methods, for example, memorization, compensation, effective, and social strategies. However, the main problem is that every one of these language strategies fits with different groups of individuals. A similar method is not generally followed by similar outcomes, and every person reaches the best result with his/her proper strategy. Hence, the learning styles of individuals are different, and every person needs to discern his/her appropriate strategies and prefer them to others (Hashim, Yunus, Hashim, 2018). Thus, the important point is that the person-fit employment of this diverse spectrum of language learning strategies in the educational system.

On the other hand, language teaching, the teaching method, and its extensiveness have always faced some criticisms. English learning and its rooted impacts have been the source of several debates in the mother tongues and cultures of numerous non-English countries. Iran is also among the much-disputed countries in this regard. Among the significant criticisms imported to English language teaching generally, and not specifically in our country, we can refer to linguistic imperialism or language hegemony. Linguistic imperialism is a term first introduced by Robert Phillipson (1992) in his book with the same title. Phillipson does not consider English expansion detached from the policies of dominant countries. In this book, he tries to picture the effects of English dispersion throughout the world as a colonialism tool of the British Empire and, then, the United States. In his mindset, concurrent with the globalization that occurs in different educational, economic, commercial, and recreational dimensions, English is advancing to extend its penetration into developing countries (Montero, 2018). The linguistic imperialism problem is an important factor compelling governments to consider their educational programs more meticulously toward the furtherance of this language. Resistance against this subject, especially in first-world countries and without colonialism heritages, has been escalated. In colonial countries, like India, English was widespread for long periods to the extent that it has now been transformed to one of the 
two main languages in this country; the language that, along with Indian, is the country's formal language and is used in administrations and educational systems and, as a lingua franca, among many diverse Indian languages. However, Iran is one of those countries that seriously resist the linguistic imperialism topic, and English has not prevailed in this country easily. On the other hand, the opponents of the linguistic imperialism idea believe that English, as a widespread language at the global level, should no longer be considered a characteristic of its mother tongue. This language has now been converted to a global property, and the scope of its different versions has also been expanded. Therefore, as far as it is related to culture, the culture of the mother tongue is no longer imposable due to the diversity in mother tongues, on the one hand, and the heterogeneous population of non-native individuals, on the other. In addition, in contrast to the linguistic hegemony idea, non-native speakers of English may use this language to express, react, or even advertise their ideas in order to influence a fairly wider part of the world, including native speakers (Talebinezhad \& Aliakbari, 2001).

Another problem considered by criticizers in discussions about the English language is subtractive bilingualism. Cummins divides bilingualism into two subtractive and additive categories and makes distinctions between them. Additive bilingualism occurs when the first language continues its expansion besides teaching and developing the second one, and the first language and culture preserve their worthy positions. However, subtractive bilingualism takes place when the second language is expanded to the extent that it overshadows and marginalizes the first language and culture (Shoebottom, 2018). Subtractive bilingualism is a noticed issue in the modern world wherein languages and cultures are communicating with each other. In such an era, languages or cultures may be neglected or subtracted easily by falling behind the cycle of international competitions in persuading individuals. The expansion of English to domains once filled with the first language can decline individuals' competencies in this language, especially if it occurs at schools, universities, and, generally, educational domains. Hence, cautiousness about subtractive bilingualism is vital when teaching a second language.

\section{Review of Literature}

Some papers have been compiled concerning the modification of teaching methods and the application of modern approaches. Some of them have investigated the current instruments of education and suggested some actions for their improvement. For example, Babai and Sadeghi (2009) examined the characteristics of an English teacher from teachers' and their students' perspectives. This field study, which distributed a questionnaire among 59 English teachers and 215 language learners at the universities, schools, and language institutions of Iran, uncovered a noticeable difference between teachers' and students' perspectives about some characteristics of a teacher. The results of the research revealed that assigning homework, presenting group activities in the classroom, using lesson plans, and applying standard assessments were instances of effective practices. On the other hand, students believe that teachers' use of the first language (Farsi) is one of the characteristics of effective teachers. Furthermore, teachers consider mastery over the target language, proper knowledge of the educational field, and the use of specific methods and techniques necessary for effective teachers. However, students accentuate the features associated with teachers' personalities and their behaviors. In another field study, Alimorad and Tajgozari (2016) investigated the attitudes of Iranian high school students and teachers toward an effective teacher. In this research, conducted by questionnaires, 57 teachers and 202 students participated from different cities of Iran. The results showed that although students preferred communicational and social methods for language learning, their teachers tended to follow traditional approaches. Furthermore, despite the statistically undispersed perceptions of students, they were considerably different from teachers' attitudes.

Apart from the discussions about teachers in academic education, another noticed problem is the topic of textbooks. In their course of study, Ahmadi and Derakhshan (2016) investigated language teachers' perceptions of textbook evaluation. This paper sought to review and evaluate different textbooks taught by English language teachers all over the world in order to probe their perceptions of the strengths and weaknesses of these educational books. Their results showed that teachers had varied perceptions associated with different textbooks, implying that teachers could tailor textbooks with students' needs. This kind of research assists textbook developers to take the subject order, vocabulary and grammatical points, language skills, language teaching methods, and book appearance into account. These researchers also provided textbook writers with some suggestions pertaining to modifying or revising the books for the purpose of meeting students' needs.

In addition to evaluating books and teachers in educational respect, there are some studies regarding learning strategies as well. In 2015, Yougen Lou conducted a field study on 115 non-English freshmen at one of the Chinese universities and compared the traditional and modern content-based language teaching methods. Content-based instruction (CBI) is a method that teaches the content and information to students in the language they are learning without attempting to teach the language, separated from the teaching concept. The results of this research, conducted on two randomly-selected groups for a single semester, revealed that content-based English language teaching could improve students' motivations and abilities in language learning. However, CBI 
is not suitable for weak language learners lacking robust bases.

Contrary to the efforts made for the applied improvement and expansion of English, some criticisms have also been imported to this linguistic expansion. In a paper published in 2014, Aghagolzadeh and Davari talked about the critical and growing thinking method born in the Iranian English-teaching society. This paper endeavored to examine and highlight the critical debates and studies in this area. These works consider language teaching globalization and its norms and methods a non-neutral and hegemonic process and are categorized into three groups: linguistic imperialism, the nature and efficiency of instructional materials, and critical teaching. The authors believe that the development of studies with political and ethical motives in these areas reflects an upsurge of critical awareness. In another study, Mastoi, Ali Lohar, and Ali Shah (2018) investigated linguistic imperialism and colonialism in India. The authors of this paper intended to mirror the traces that the dream of mastery over the English language engendered in India under the direct influence of the British Empire, the traces that linguistic imperialism is among the most important ones. This paper pursued the linguistic imperialism characteristics resulted from the industrial economy plan. English was first taught to the Indians for commercial purposes, and then it gradually entered colleges, universities, and other educational centers. In this period, a mass of people turned to learn English in order to achieve better occupational positions, and this language was soon connected to a type of social class as well. The authors believe that Britain first attended this country for commerce; however, it influenced India immediately, and these changes reached linguistic imperialism shortly after the entry of the East India Company to this country.

Another criticism imported to the English language expansion is the subtractive bilingualism problem. Mathe (2016), in his paper, examined how subtractive bilingualism impacted the university performance and first language of students of minority languages. By reviewing the related literature, this paper concentrated on students of social classes with ethnic and linguistic minorities in high schools. The research argued that subtractive bilingualism impacted the capability of using the first language. According to the results of another study, also cited in this paper, field learning through another language resembles a sense of detachment from the mother tongue and culture and is detrimental to students. Students' lack of opportunities to use their first language in the school environment and intensive and almost compulsory utilization of a new language as an instructional means marginalize their first language more than ever. Language loss or change makes the speaker start using a newly learned language and abandon utilizing his/her first language in school domains and social institutions. Another negative consequence is that the first language of the speaker becomes unstable by time. Hence, we can assert that students' first languages are the ones that experience the maximum impairment in this process.

\section{The Research Filed, Method, and Questions}

This research specifically investigated the English language teaching problem and its derived criticisms among anthropology students in the Faculty of Social Science in Tehran University. It pursued a case study method and mainly employed semi-structured deep interviews. During the research, several of these students at different B.A. and M.A. levels were interviewed randomly. The field work terminated with 20 interviews when the amount of received data and considered information reached saturation, and new individuals did not present new information.

Three questions were generally raised in this research: First, did students perceive the instructions presented in school and university academic courses sufficient and satisfactory considering the needs they faced at different educational levels? If not, did they agree with English development and the utilization of alternative and more applied methods in the educational system? Second, since the examined cases were the students majoring in social sciences, they were required to analyze the imported criticisms to English language expansion in society and explain their respective opinions as individuals who had the necessary education for investigating social problems. Third, considering the discussions, social needs, and opponents' criticisms, the interviewees were required to suggest a language expansion program both meeting social needs and preventing the Farsi language and culture from being influenced.

The Common European Framework of Reference (CEFR) standard was used for determining the language levels of interviewees in this research. This standard is a criterion for identifying individuals' levels of success in learning a foreign language and encompasses three basic, independent, and proficient levels described below (Using the CEFR, 2011):

Basic level: Learners can comprehend recurring sentences and expressions in highly related fields, for example, the primary information associated with individuals, families, shopping, local geographies, and occupations. They are capable of understanding and using daily and basic expressions to meet their initial needs, introducing themselves and others, and responding to questions related to their personal details, like where they live. If other negotiations flow smoothly and clearly, they can simply establish relationships with others.

Independent level: Learners can comprehend main textually complicated concepts about specific and abstract topics, such as technical discussions about their specialized areas. They can cope with many emerging 
conditions when traveling to a region wherein their considered language is spoken. They can create cohesive texts about unfamiliar or personally interested subjects, describe their experiences, narratives, dreams, and hopes, and present explanations and reasons for their perspectives and plans.

Proficient level: Learners almost comprehend anything they read or hear. They can restructure information from different verbal and written sources and express it fluently and accurately. They are capable of understanding a wide spectrum of sophisticated texts and discern delicate semantic differences even in complicated conditions. Furthermore, they can employ adaptable and effective language for their social, university, and professional purposes.

To obtain the interviewees' levels of language skills, they have been asked to specify to which level they fell by using these standards and relying on their awareness of their linguistic knowledge and skills in varying linguistic areas.

\section{Findings}

6.1 Making English more extensive at schools

A more applied expansion of English for use in the scientific domain constitutes the main axis of this research. Thus, to acquire knowledge of the interviewees' perspectives, the researchers first questioned their skillfulness in this language and their familiarity with other ethnic or foreign languages. A large number of these individuals possessed elementary acquaintance with one or two ethnic or foreign languages, and English was not the mere second language they had encountered. However, they mostly had independent-level language skills, which needs to be discussed. Since Iranian education at schools and even private institutions minimally focuses on writing, many interviewees fell into the basics' group regarding this skill. Speaking was ranked second, and many respondents had an elementary knowledge of this skill. Listening was ranked third skill since they mostly used to watch films and serials or listen to music. Finally, they considered themselves most skillful in the reading skill, which was not far-fetched owing to the focus of the educational system on reading reinforcement. However, on average, we can explain that many of the interviewees had independent levels of English.

In answering the first question of the interview concerning the effect of school education on learning language skills, many interviewees did not refer to the educational system of the country. They, rather, asserted that they had learned this language outside the school with the aid of private academies or family members since they were in guidance or elementary schools. One of the interviewees answered that: "I can say I learned this language mostly at home. My mother is an English teacher. She was practicing this language with me from my childhood." Another interviewee described his language learning method as follows: "I did not attend any private institution until the high school. Before that time, my elder brother taught me the alphabet or simple words outside the home using boards and banners. When I was in high school, I went to an institution for one or two semesters, but I then gave up and turned to self-study. At that time, I used the Oxford Storybook Series. These books were read by a native speaker to the audience. Individuals had to listen to these stories, each consisting of six lines, and look at the text simultaneously. This act should be repeated for seven days, and I had used this method dispersedly for several years till I entered the master course. Since I was obliged to read specialized articles, I turned to language learning more, such that I passed ILETS courses as well'. However, many interviewees, except for these examples, recognized private language teaching centers as their main learning sources.

Numerous interviewees referred to the significant role of language in their lives, and they were struggling to learn the advanced levels of language. Some of them were compelled to spend time and learn this language by entering the university, especially the master's course, to coordinate themselves with the university criteria and lessons presented in this period. Some were also improving their language skills in order to take international language exams, like TOFEL and ILETS. In any case, all these individuals were pursuing to learn the language for some, mostly educational, reasons after several years of studying at schools and universities.

However, there were three kinds of feedback among the interviewees concerning the expansion of English in the educational system. The first group members, constituting the majority of the interviewees (13), were in complete agreement with this topic and, in their examples, named several private schools in Tehran city that were following the same method at that moment. These individuals believed that if the formal educational system of the country took the same steps and exerted changes in the language teaching method to be not only concerned with language grammar and reading skills but also with studying the lessons in different spheres, writing academic essays, and try to communication, these instructions would be more effective. Nonetheless, both the members of this group and almost all interviewees believed that the main problem was the incorrect educational system at schools. In their mindsets, the language teaching method of schools and, sometimes, the teaching methods of all courses should first change for the expansion of English usage in education. In their opinions, the current method was inefficient and ineffective, the conception that was also reached from their references to how language was learned. These individuals believed that neither books and teaching methods nor teachers and professors operate efficiently and follow standard methods in teaching English or any other 
language. That is, if a person is solely dependent on the school education, she/he will not be able to communicate a simple message. In their beliefs, the main reason students go to language classes outside schools lies in the inefficiency of school teaching. However, the primary problem is that these institutions teach language to learners at general and everyday levels, the skills used for establishing relationships with a native person in general locations, listening to music, or watching films or serials. But language learning at formal and academic levels, used for reading specialized books and articles, writing essays and papers, or speaking with specialists in a scientific field, is not the thing these institutions can teach to their language learners. Perhaps, this is a responsibility that the educational system of the country should undertake. The acquisition of skills in these cases form the basis of entering the international scientific world. Unfortunately, these aspects have not been addressed in the educational system of Iran correctly.

The second group had a more radical perspective. The members of this group believed that English should be taught to students from primary school besides the Persian language. There were three interviewees with this outlook. Teaching by a language other than the mother tongue has been always discussed, especially in our country. Many ethnic groups believe that there should be a place in the educational system for teaching through the ethnic language besides Farsi. It is because learning a new language, along with learning lessons, lowers the scores of those students who do not have adequate mastery over Farsi and makes them fall behind their Farsispeaking peers. This is what happens to Farsi-speaking students at postgraduate and international levels when they encounter the English language. On the other hand, several researchers claim that language learning is more effective when it starts at younger ages since it seems that our brain is more responsive to language in the early years. Numerous studies on bilingualism and second language learning also share a point: the earlier, the better. It is because the language learning capacity and preservation of linguistic delicacies decline as one gets older (Heinlein, William; 2013). Thus, to start learning a language at younger ages, students need compiled programs that do not prevent them from learning and progressing and teach them language at lower levels.

In contrast, there is a third group who disagree with this topic and believe that the idea of expanding English to other lessons and pre-university levels is just an extra burden shouldered by students. Among three interviewees with this viewpoint, one explained her opinion as follows: "At present, schools teach sufficient and different specialized courses to students, many of which are not interested in the majority of these courses and even believe that they will not impact their future after the high school. They dislike attending university and studying in the scientific domain. Therefore, the addition of English to these courses may aggravate the conditions to these students and distance them from the school and lessons more than ever". These interviewees imagine that selecting language learning for further use should be voluntary and the responsibility of students.

\subsection{Role of Language Teaching Expansion in Blurring Mother Language and Culture}

Concerning the criticisms imported to English expansion in the country, such as linguistic imperialism and subtractive bilingualism, we can claim that the responses of the interviewees generally included three points. First, with respect to the present technological advancements and the emergence of numerous social networks, familiarity with the western culture and being influenced by it are inevitable in any concern, whether English teaching is expanded or not. According to this perspective, in the modern globe, individuals are familiar with the off-limit world and diverse languages and cultures in different occupational, educational, and recreational respects. Working for international firms, studying at international universities inside and outside the country, dealing with different foreign articles and books, watching films and serials, enrolling in social networks, and communicating with the people in the world constitute the factors not only acquainting specific groups but also the public with the languages and cultures of other countries in the globe. Thus, the main problem associated with the impact of other cultures is not solely dependent on language teaching, and there exist other prior reasons, the most primary of which is the problem of globalization in all dimensions of individuals' lives.

The introduction of this topic makes us reach the second point in these responses, i.e., the deficiency of the native culture and domestic educational system. Now that all countries and cultures, and not just our nation, are communicating and interacting, the failure of our values, culture, and first language in adapting to the new age and introducing themselves to the world is the factor that marginalizes the Farsi language and culture and leads to subtractive bilingualism. In a world in which familiarity with another language takes place either by learning it or through media, communications, and culture transference, neglecting the dynamics of the first language and culture will also overshadow and marginalize them. Many interviewees believed that Farsi is being subtracted gradually due to the lack of any effort for supporting this language. In their mindsets, teaching, introducing, and reinforcing the old Farsi culture, literature, and art attractively and according to modern methods can confront the blur of the native culture. On the other hand, by fortifying the Farsi language and culture and updating them with the help of English, we can introduce them to the globe. This is what other countries in East Asia, like Korea, China, and Japan, are implementing. The main problem in these criticisms and disagreements with language expansion is that we cannot preserve our mother tongue and culture and transfer it to the new generation by closing our boundaries to the world and focusing on these two. In a world in which a new object is 
invented and offered at a dazzling pace, missing the boat of advancement and globalization is the reason for the marginalization of the mother tongue and culture by itself. On the other hand, many interviewees argued that these criticisms only covered up the disabilities of the educational system in teaching a foreign language to students. For example, an interviewee believed that: "if the sole problem is the negative effect of English on our first language, why has not Arabic, which is also the language of our religion, and many efforts have been made for its teaching, been taught correctly"? Individuals' mastery over Arabic is much weaker than English in Iran, although this language is taught concurrently with English and with the allocation of equal educational hours. The mere difference is that students do not refer to private institutions to learn this language.

The third point is that some interviewees conceived that this language was needed in all domains, especially in the scientific domain and universities, to the extent that we could not ignore it even at the expense of the marginalization of the mother tongue. In this respect, an interviewee explained that: "All people are aware of the need for English, and many are learning this language. Policy-makers should be realistic and consider the conditions of the country and the world. Now that individuals are learning this language, they should steer this training toward the formal education system in a correct way". The English language is the vehicle for communicating with the world, and we cannot deny it at all. On the other hand, if we are to limit the learning of this language or put it aside, we should translate all texts and papers into Farsi in order to fill this gap; unfortunately, this domain experiences weaknesses as well. However, if we even assume that there is a strong language translation system in the scientific domain, we, again, need English mastery to communicate with other universities, professors, conferences, and the world's academic environments. Not teaching this language does not remove any problems, and the country should pursue reinforcing the Farsi language and culture concurrent with the world and its changes besides introducing foreign languages in order to cope with this problem.

Along with these perspectives, two interviewees defended some of these criticisms, not in a sense that we should not take any step for the current inefficient system and ignore the crucial role of the language; rather, they agreed with the impact of language learning on culture, lifestyle, and the applied non-Farsi lexeme scope. Many individuals considered by these two interviewees were the ones intending to immigrate to western countries or were living there. However, despite such effects of the western culture, the main problem still lies within the country and in cultural, economic, or even political issues. Many individuals leave the country to attain the higher welfare offered in developed countries. Furthermore, many do not have an opportunity to reveal the Farsi culture and language or transfer them to their children since our language and culture are unknown in the current modern world and own no position in science, policy, art, and entertainment. Thus, we have to eliminate domestic deficiencies in order to inhibit this trend.

\subsection{Methods for Improving the Educational System}

The third question asked from the interviewees in this research concerned with their suggestions for changing the education system and making it more efficient, such that it became more successful in language teaching and did not alter the role of Persian language and culture. As aforementioned, many participants in this research thought that the reason for the low language proficiency of students and the blurring risks of the mother tongue and culture lay in the efficiency of the country's educational system. The educational system neither teaches the language effectively nor familiarizes students with Farsi history, tradition, culture, language, and literature. However, it seems that the deficiencies of individuals in these domains, where the strengthening of one impedes the development of the other according to some viewpoints, are mainly rooted in the absence of a balanced and efficient system with up-to-date methods tailored to individual tastes.

Different suggestions were posed by the interviewees in this respect, for example, replacing language teachers at schools and employing specialized and trained teachers in this field, increasing the number of voluntary courses presented in English at schools and universities, creating in students a sense of need for English, and enabling individuals' access to education either privately ore at schools. They also proposed further dealing with and reinforcing the Farsi language and culture, creating attractive content in Farsi, making the educational methods research-oriented, and developing a participatory atmosphere, wherein individuals get acquainted with the need for the language and attempt for its improvement during their research processes. Offering some courses for reinforcing language skills, like presentation and essay writing in English, and presenting voluntary courses in English, like the method pursued in international campuses, were among the other recommendations of the interviewees. They also suggested using the books and teaching methods applied by private language institutes and adopted from the teaching methods of the native countries of this language at schools, initiating language teaching from early ages, creating refresher and extra courses for those students who were low-achievers and could not attend private institutes for different reasons, and allocating some courses for teaching specialized courses in English.

\section{Conclusion}

In the modern world, where everything is moving and advancing at an unprecedented pace, communicating with 
others has the most significant contribution. In order not to miss the boat, governments and nations need to interact with the rest of the world. Science and knowledge also possess privileged positions in this globalization system. The scientific world is in relationship with others in the various parts of the world more than other domains. However, this relationship firstly requires a mutual language over which individuals need to have adequate mastery in order to take part in this connected globalized world. The topic that embraces the main question of this paper is: Do we really have sufficient mastery over this international language to interact with the world?

The answer is absolutely negative. According to the results of this research, it seems that the primary reason for the inefficiency of the country's educational system is that it does not prepare students for entering this domain. Many individuals owe their language skills to private institutions and believe that school and university teaching is fruitless and fundamentally problematic. Hence, many of these individuals agree with changing the educational system in this area and employing more applied methods to expand language teaching in all skills, including reading, writing, speaking, and listening. On the other hand, these individuals rejected the criticisms imported to language expansion and believed that the subtraction of the mother tongue and marginalization of the Persian language and culture stemmed from internal inattention to this problem. They mainly conceive the failure of the native culture in attracting the new generation and adapting to the modern era as the primary factor leading to the negligence of the mother culture and believed that this condition also occurs irrespective of the English expansion. Accordingly, to promote the mother tongue and culture and retain it properly, we'd better entertain some programs in step with the modern age. Similar to what many countries are now pursuing, these programs can also be introduced to the world with the aid of the international language and reflect the Persian language and culture to the world's inhabitants.

\section{References}

Heinlein, K. Byers; Williams, C. Lew. (2013). Bilingualism in the Early Years: What the Science Says. Learn Landsc; 7(1): 95-112.

Shoebottom, P. (2018). The language learning theories of Professor J. Cummins. [ONLINE] Available at: http://esl.fis.edu/teachers/support/cummin.htm.

Hashim, Haida Umiera; Yunus, Melor Md.; Hashim, Harwati. (2018). Language Learning Strategies Used by Adult Learners of Teaching English as a Second Language (TESL). TESOL International Journal, v13 n4 p39-48.

O'malley, J. M., O'Malley, M. J., \& Chamot, A. U. (1990). Learning strategies in second language acquisition. Cambridge university press.

Chamot, A. U. (2005). Language learning strategy instruction: Current issues and research. Annual review of applied linguistics, 25, 112-130.

Montero, Luis. (2018). Phillipson's Linguistic Imperialism Revisited at the light of Latin American Decoloniality Approach. Revista Electrónica Educare (Educare Electronic Journal), 1409-4258 Vol. 22(1).

Using the CEFR: Principles of good practice. (2011). university of Cambridge.

Naji Meidani, Elham. Pishghadam, Reza. (2013). Analysis of English language textbooks in the light of English as an International Language (EIL): A comparative study. International Journal of Research Studies in Language Learning, Volume 2 Number 2, 83-96.

Ahmadi, Azam. Derakhshan, Ali. (2016). EFL Teachers' Perceptions towards Textbook Evaluation. Theory and Practice in Language Studies, Vol. 6, No. 2, pp. 260-267.

Tomlinson, B. (2005). English as a foreign language: matching procedures to the context of learning. In E. Hinkel (Ed.), Handbook of Research in Second Language Teaching and Learning (pp. 137-153). London: Lawrence Erlbaum Associates.

Talebinezhad, M. R., \&Aliakbari, M. (2001, July).Basic Assumptions in Teaching English as an International Language.The Internet TESL Journal,7(7).Retrieved from http://iteslj.org/

Aghagolzadeh, Ferdows; Davari, Hossein. (2014). Iranian Critical ELT: A Belated but Growing Intellectual Shift in Iranian ELT Community. Journal for Critical Education Policy Studies, v14 n1 p391-410.

Mastoi, Ruqia Bano; Ali Lohar, Shoukat; Ali Shah, Syed Waqar. (2018). English Colonialism and Imperialism in India. Journal of Literature, Languages and Linguistics, ISSN 2422-8435, Vol.48.

Babai Shishavan, Homa; Sadeghi, Karim. (2009). Characteristics of an Effective English Language Teacher as Perceived by Iranian Teachers and Learners of English. English Language Teaching 2(4), DOI: 10.5539/elt.v2n4p130.

Alimorad, Zahra; Tajgozari, Mostafa. (2016). A Comparison of Iranian High School Teachers' and Students' Perceptions of Effective English Teachers. SAGE Open 6(4) DOI:10.1177/2158244016679212.

Lou, Yougen. (2015). An Empirical Study of Content-Based Instruction Applied in Non-English-Majored Graduate English Teaching in the Post-Massification. Creative Education, 6, 1578-1583. doi: $10.4236 /$ ce. 2015.614158 
Giddens, Anthony. (1999). Runaway World: How Globalization is Reshaping Our Lives 1st Edition. Published December 26, 2002 by Routledge.

Mathe, S. S. (2020). HOW DOES SUBTRACTIVE BILINGUALISM AFFECT THE ACADEMIC PERFORMANCE AND L1 OF STUDENTS FROM SOCIAL GROUPS WITH LOW ETHNOLINGUISTIC VITALITY? [ONLINE] Available at: How does subtractive bilingualism affect the Academic performance and L1 of students from social groups with low Ethnolinguistic Vitality? | REVISE - Revista Integrativa em Inovações Tecnológicas nas Ciências da Saúde (ufrb.edu.br). 